\title{
Psychometric Validation of the Internet Disorder Scale-Short Form in an Italian Adult Sample
}

\author{
Paolo Soraci $^{1}$ - Ambra Ferrari ${ }^{2}$ - Enrico Bonanno ${ }^{3} \cdot$ De Pace Rosanna ${ }^{1}$. \\ Emanuela Repice ${ }^{1} \cdot$ Mark D. Griffiths ${ }^{4}$
}

Published online: 27 April 2020

(C) The Author(s) 2020

\begin{abstract}
Research examining online addictions has conceptualized generalized internet addiction as an "umbrella" term comprising the addictive use of various online activities such as gambling, gaming, pornograpgy consumption shopping, and social media use. This has led to the development of many different psychometric instruments to assess specific forms of online addiction as well as ones that assess disordered internet use more generally. One such scale is the nine-item short-form Internet Disorder Scale (IDS9-SF) based on the DSM-5 criteria for internet gaming disorder. Although the IDS9-SF has been validated in a number of languages, it has not been validated into Italian. Therefore, the present study validated the IDS9-SF utilizing an Italian-speaking sample $(N=1477)$. Data were initially collected from 963 participants and the sample was equally split to carry out exploratory factor analysis (EFA) and confirmatory factor analysis (CFA) on the Italian IDS9-SF. Results showed that two items were problematic (i.e., in terms of asymmetry and kurtosis) so a slightly modified Italian IDS9-SF was developed (modifying the two items). Data were then collected from a further 514 participants to test the modified Italian IDS9-SF. The second sample was again equally split, and EFA and CFA were carried out. The modified Italian IDS9-SF was found to be a psychometrically robust measure for assessing the risk of internet disorder among Italian adults.
\end{abstract}

Keywords Internet addiction · Internet disorder · Internet disorder scale · Online addiction · Behavioral addiction $\cdot$ Psychometric testing

The recognition of internet use as being potentially addictive dates back to the mid-1990s (Griffiths 1996; Young 1998). Depending upon the scientific focus (e.g., psychological,

Open Access This article is distributed under the terms of the Creative Commons Attribution 4.0 International License (http://creativecommons.org/licenses/by/4.0/), which permits unrestricted use, distribution, and reproduction in any medium, provided you give appropriate credit to the original author(s) and the source, provide a link to the Creative Commons license, and indicate if changes were made.

Mark D. Griffiths

mark.griffiths@ntu.ac.uk

Extended author information available on the last page of the article 
neuroscientific, or psychiatric), problematic internet has been referred to as pathological internet use (Kaess et al. 2016; Wartberg et al. 2015), virtual addiction (Greenfield 1999), internet addiction (Pontes et al. 2015; Petry et al. 2018), and compulsive internet use (Greenfield 1999). Despite different definitions, conceptualizations, and controversies (Griffiths et al. 2016), Internet addiction (also referred to as internet use disorder) can be generally characterized as an impulsive control disorder similar in some ways to behaviors such as gambling disorder (Ko et al. 2010; Young 1998) and internet gaming disorder (IGD) (Király et al. 2014; Pontes et al. 2014). Based on the instrument used to assess the disorder in the present study, the present study uses the term "internet disorder" (ID).

The latest (fifth) edition of the Diagnostic and Statistical Manual of Mental Disorders (DSM-5) underlined the increasing theoretical and empirical interest in behavioral addictions (i.e., gambling disorder in the main text, and internet gaming disorder [IGD] in Section III ["Emerging Measures and Models"]). Research examining online addictions has conceptualized generalized internet addiction as an "umbrella" term comprising the addictive use of various online activities such as gambling, gaming, pornography consumption, shopping, and social media use.

In the past 10 years, research has demonstrated how individuals affected by ID can display several behavioral disturbances (Shapira et al. 2000). Such determinants include poor control over internet use, increased stress, and total preoccupation, leading to a variety of negative consequences on their private life including problems with their relationships and/or occupation or education depending upon their age (Weinstein et al. 2014). ID has also been associated with insomnia and other sleep problems (Alimoradi et al. 2019; Lam et al. 2009), social anxiety (Weinstein et al. 2015), and poor academic performance (Jun and Choi 2015; Reed et al. 2015; Rücker et al. 2015). In some research, ID has also been associated with attention-deficit/hyperactivity disorder, anxiety, depression, and other impulse control disorders (Banjanin et al. 2015; Sariyska et al. 2015) which can even lead to suicidal tendencies in extreme cases (Alpaslan et al. 2015).

Although there are similarities between ID, gambling disorder, and IGD with regard to behavioral consequences such as impulsivity, the concept of ID is still controversial and there is disagreement among scholars as to whether it really exists, and if it does exist, how it should be conceptualized (Griffiths et al. 2016). An important difference alluded to earlier is the difference between generalized online addictive behavior (i.e., Internet addiction) and specific online addictive behavior (e.g., IGD) with both theoretical and empirical evidence demonstrating that they are conceptually different (Griffiths \& Pontes, 2014; Király et al. 2014; Montag et al. 2015). Furthermore, despite the empirical evidence that ID can be conceptualized as a behavioral addiction, being able to distinguish between internet addiction and excessive internet use can sometimes be difficult (Lee et al. 2014). Furthermore, it is not clear if ID can be defined as a primary disorder itself or if it is a secondary disorder that is a consequence of other major mental disorders such as depression and anxiety (Pies 2009).

In addition, the internet may simply be a medium through which other disorders manifest (Block 2008) or be a medium that facilitates other behavioral addictions (Griffiths 1999; Pontes et al. 2015). The DSM-5 (wrongly) stated that IGD was also known as "internet use disorder" and asserted that if an individual endorses at least five of nine proposed criteria for a minimum period equal to 12 months that they could be diagnosed with IGD (or internet use disorder). The nine criteria incorporate Griffiths' (2005) six core components of addiction (i.e., salience, mood modification, tolerance, withdrawal symptoms, conflict, and relapse) which have previously been used to conceptualize several technological addictions (Griffiths 1995, 1996, 1998, 2005; Marks 1990). 
In the context of ID, salience refers to the need to constantly use the internet to the extent that it dominates the individual's thoughts, behavior, mood, and feelings. Mood modification refers to the individual using the internet to provide a consistent and reliable shift in their mood state. Tolerance refers to the need for an individual to increase the amount of engagement with the internet in order to achieve the same initial mood-modifying effect. Withdrawal refers to both physical effects (e.g., nausea, stomach cramps, panic attacks) and psychological effects (e.g., extreme moodiness, irritability, frustration) as a consequence of either decreasing or ceasing internet use. Conflict refers to internet use compromising personal relationships, occupation and/or education, and intrapsychic conflict (e.g., experiencing a subjective loss of control concerning their internet use). Finally, relapse refers to an individual re-engaging in internet use again following a period of self-enforced abstinence.

Despite the existence of frameworks defining ID and internet addiction, the phenomenon still presents with conceptual difficulties. Király et al. (2014) published a comprehensive review and found three major inconsistencies in the nine most used instruments for assessing the risk of ID and internet addiction (i.e., theoretical limitation of the instruments, factor structures of the instruments, and the psychometric properties of the instruments). More considered models (such as the cognitive-behavioral model by Davis 2001) present operational difficulties in terms of capturing and distinguishing between the different aspects of the behavior on the ID spectrum (Pontes et al. 2015).

Consequently, a standardized psychometric tool that incorporates ID complexity, as well as robust psychometric properties able to estimate ID prevalence and diagnose the risk of having ID is of paramount importance in the field. Pontes and Griffiths (2017) developed the 15-item internet Disorder Scale (IDS-15) based on the DSM-5's diagnostic criteria for internet Gaming Disorder (APA 2013). The IDS-15 assesses generalized internet disorder via the following domains: (i) escapism and dysfunctional emotional coping, (ii) withdrawal symptoms, (iii) impairments and dysfunctional self-regulation, and (iv) dysfunctional internet-related selfcontrol. The scale reported robust psychometric properties, and the nine-item short-form (IDS9-SF) reported equivalent psychometric robustness as the IDS-15, but with a simpler factor structure (Pontes and Griffiths 2016).

To date, these scales have been validated into various other languages but have never been validated into Italian. The validation of instruments such as the IDS9-SF is important in order to collect and compare empirical worldwide evidence. Consequently, the objectives of the present study were to (i) validate and psychometrically test the Italian version of the IDS9-SF test utilizing confirmatory factor analysis (CFA), and nomological analysis, (ii) assess internet disorder in an Italian sample using the Italian IDS9-SF, and (iii) assess whether the Italian IDS9-SF is unidimensional.

\section{Methods}

\section{Participants}

Participants were recruited by posting links to an online survey on online forums and social network communities (Facebook, LinkedIn, Instagram). A total of 1477 participants (comprising two different samples, 963 in Sample A and 514 in Sample B, both recruited using convenience sampling) voluntarily completed an online survey which took around 15-20 min to complete. The period of data collection spanned from October to November 2019 and, in 
both samples, the only exclusion criteria used were being at least 18 years old and to be an Italian-speaking citizen. All the participants completed the survey anonymously and gave informed consent for the analysis of their data.

\section{Measures}

Sociodemographic Parameters and General Internet Use The survey included questions regarding sociodemographic information (the participant's gender, age, and educational level).

Internet Use and Other Life Habits The survey included single-item questions concerning the participant's general internet use, including the average daily hours spent online, online weekly shopping frequency, and online weekly pornography use. Such variables were included because they have been associated with online addictions (e.g., Trotzke et al. 2015). Other questions were asked regarding life habits such as the weekly frequency of cigarette smoking, alcohol use, and illicit drug consumption, assessed on a five-point Likert scale ranging from 1 (never) to 5 (very often). These variables were included because they have been associated with online addictions (i.e., Pontes and Griffiths 2016).

Quality of Life and Sociability The survey also included a question on the perceived quality of life ("How satisfied are you with your life?", assessed on a five-point Likert scale from 1 (very little) to 5 (very much) because addictions often affect quality of life (e.g., Ezoe et al. 2009). Questions concerning the perceived degree of sociability ("Do you consider yourself to be sociable online?") and the perceived anxiety of performing actions in public (such as eating or speaking) were also included, and both were answered on a Likert scale from 1 (very little) to 5 (very much). Another question asked was "How often do you make friendships or have romantic relationships with people you know online through online chat, forums or social networks?", assessed on a five point Likert scale from 1 (never) to 5 (very often). These specific questions were included to examine how sociable participants perceived themselves in their daily life because previous research has shown those with addictions can have socialization problems (e.g., Lin et al. 2015).

Italian Internet Disorder Scale-Short Form (IDS9-SF) The nine-item IDS9-SF is a unidimensional and standardized instrument that assesses internet use disorder. It was developed by Pontes and Griffiths (2016) as a shorter version of the IDS-15 scale (Pontes and Griffiths 2017). The nine items were adapted from the nine criteria for IGD in the latest (fifth) edition of the Diagnostic and Statistical Manual of Mental Disorders (DSM-5). As reported by Pontes and Griffiths (2016), the items assess salience, mood modification, tolerance, withdrawal symptoms, conflict, and relapse (Griffiths 2005) in relation to the participant's internet use. The nine items of the adapted IDS9-SF are answered using a fivepoint Likert scale from 1 (never) to 5 (very often). An example item is "Do you have difficulties in trying to control, cut down, and/or cease your online usage?" Higher scores indicate a higher degree of internet use disorder. The Cronbach's alpha in the present study is reported below in the "Results" section.

In the present study, internationally accepted practices for translation were employed (Beaton et al. 2000), and the scale was translated by Italian psychologists into Italian, and then the Italian items were back-translated by a native translator (who had never seen the scale 
before). All translators compared all forward and backward translated versions to consolidate and develop an interim Italian version of the IDS9-SF.

Bergen Social Media Addiction Scale (BSMAS) The BSMAS was originally developed by Andreassen et al. (2016), and the Italian BSMAS was validated by Monacis et al. (2017). The six-item instrument assesses social media addiction over the past 12 months using the six addiction components proposed by Griffiths (2005) outlined in the previous section. The six items are answered using a five-point Likert scale from 1 (never) to 5 (very often). An example item is "How often over the past year have you used social media to forget about personal problems?" Higher scores indicate a higher degree of social media addiction. In the present study, the internal consistency of the Italian BSMAS displayed a very good Cronbach's alpha $(\alpha=0.816)$.

Short Form of the Internet Gaming Disorder Scale (IGDS9-SF) The short form of the Internet Gaming Disorder Scale (originally developed by Pontes and Griffiths 2015) was translated and validated in the Italian context by Monacis et al. (2016). The nine-item scale assesses internet gaming severity over the past 12 months on a five-point Likert scale ranging from 1 (never) to 5 (very often). An example item is "Have you continued your gaming activity despite knowing it was causing problems between you and other people?" Higher scores indicate a higher degree of internet gaming disorder. In the present study, the internal consistency of the Italian IGDS9-SF displayed an excellent Cronbach's alpha $(\alpha=0.923)$.

\section{Ethics}

All the procedures carried out in the present study were in accordance with the Helsinki declaration and with the approval of the research team's institutional research committee. All participants were assured that their data were anonymous and confidential and that they could withdraw their participation at any time.

\section{Statistical Analysis}

Before performing data analysis, the univariate normality of the results was checked using the guidelines proposed by Kim (2013) and Muthèn and Kaplan (1985) (i.e., all items had skewness and kurtosis in the +1 to -1 range). In order to guard against potential unreliable responses, the participants were only considered as univariate outliers only if the standardized composite sum score of the IDS9-SF using all nine items scored \pm 3.29 standard deviation from the IDS9-SF z-scores. This value represents a reliability threshold, since it includes 99.9\% of the normally distributed IDS9-SF scores. The statistical analyses carried out were (i) $t$ tests to verify if gender and age affected the scale scores; (ii) descriptive statistics of the IDS9SF items (frequencies and percentages of the main items' results); (iii) nomological validation of the Italian IDS9-SF; (iv) the reliability of the scale, examined via the average variance extracted (AVE) and composite reliability (CR) (verifying whether their respective values lie above their desired threshold). More specifically, values of AVE greater than 0.5 and values of CR greater than 0.7 are associated with a strong reliability of the test (Fornell and Larcker 1981; Hair et al. 2010) and (v) evaluation of the factor structure and the dimensionality of the Italian IDS9-SF through exploratory factor analysis (EFA) and confirmatory factor analysis 
(CFA). The analyses were carried out using FACTOR (Lorenzo-Seva and Ferrando 2006), SPSS Statistics v.25 (IBM Corporation 2011), and the R package lavaan (Yves Rosseel 2012).

\section{Results}

\section{Sociodemographic Characteristics and Internet Use Patterns}

The main sociodemographic characteristics and internet use patterns for both samples are summarized in Table 1 . In sample A, 56.3\% had a university degree and $43.6 \%$ had a high school diploma. Nine-tenths of the participants (90.2\%) began using the internet before 18 years of age, $9.3 \%$ engaged in online shopping frequently (very often), and $71.3 \%$ used a Wi-Fi-enabled device frequently. In sample B, $60.3 \%$ had a university degree and $39.7 \%$ had a high school diploma. Over nine-tenths of the participants (93.2\%) began using the internet before 18 years of age, $10.3 \%$ engaged in online shopping frequently (very often), and $67.3 \%$ used a Wi-Fi-enabled device frequently.

In the following sections, the results have been subdivided into the two study samples. The only difference between the two samples is that Sample A completed the survey with the original version of the Italian IDS9-SF and Sample B completed the survey with the modified version of the Italian IDS9-SF.

\section{Exploratory Factor Analyses}

In order to carry out the EFA, Sample A was equally split into two random halves. Sub-sample 1 of Sample A (Sample A-SS1; $n=480$ ) was used for the EFA, and sub-sample 2 from Sample A (Sample A-SS2; $n=483$ ) was used for the CFA. Since there is no unequivocal consensus on the adaptation indices for the evaluation of the goodness of a model (Bollen and Long 1993; Boomsma 2000; Hoyle and Panter 1995), the EFA was conducted utilizing different indicators. In Sample A-SS1, the root mean square error of approximation (RMSEA) and comparative fit index (CFI) indexes (Cerny and Kaiser 1977; Kaiser 1974) were similar to the original version of the model $(\mathrm{RMSEA})=0.068, \mathrm{CFI}=0.986$, Kaiser-Meyer-Olkin $(\mathrm{KMO})=0.907$, and goodness of fit index $(\mathrm{GFI})=1$.

Table 1 Sociodemographic characteristics and main internet use patterns of the two samples

\begin{tabular}{ll} 
Main sociodemographic characteristics and internet use patterns - Sample A & \\
Number of participants & 963 \\
Males & $15 \%$ \\
Online shopping (very often) & $9.3 \%$ \\
Age (mean, standard deviation) & $23.1 ; 3.5$ \\
Internet average daily use (mean, standard deviation) & $6.2 ; 4.5$ \\
Internet use starting age (mean, standard deviation) & $8.04 ; 6.30$ \\
Main sociodemographic characteristics and internet use patterns - Sample B & 514 \\
Number of participants & $20 \%$ \\
Males & $10.3 \%$ \\
Online shopping (very often) & $23.2 ; 2.3$ \\
Age (mean, standard deviation) & $6.3 ; 4.7$ \\
Internet average daily use (mean, standard deviation) & $12.02 ; 3.9$ \\
Internet use starting age (mean, standard deviation) & \\
\hline
\end{tabular}


However, when analyzing the descriptive statistics, it became apparent that Item 7 ("Have you deceived any of your family members, therapists or other people because of the amount of time you spend online?") and Item 9 ("Have you jeopardized or lost an important relationship, career or an educational opportunity because of your online usage?") of the Italian IDS9-SF displayed some inconsistency compared with other items and presented much high asymmetry and kurtosis (i.e., > 3). More specifically, their asymmetry in the response distribution showed a non-normal behavior with high skewness and kurtosis. In particular, Item 9 displayed a skewness of 3.26 and kurtosis of 11.20. As for the univariate normality (skewness and kurtosis between +1 and -1 in all items, (Muthén \& Kaplan, 1985)), some items of the IDS9-SF had absolute values of skewness $>3.0$ and kurtosis $>8.0$ (Kline 2011) therefore supporting the univariate non-normality of the main measure. Because of this, the data were then analyzed utilizing polychoric correlations and parallel analysis (PA) with diagonally least weighted squares (DWLS) estimator.

In order to investigate this inconsistency and whether it was due to the two items, an adapted IDS9-SF scale was used which slightly modified Item 7 ("Have you lied to your family, friends, therapists or other people about the amount of time spent online on the internet?") and Item 9 ("Have you put at risk or compromised an important relationship, your career or your studies because of your use of the internet?'). In this modified version of the IDS9-SF, Items 7 and 9 were translated by two different native speakers who had never seen the test before. The wording was slightly changed but maintained the original meaning.

Consequently, Sample B (who were given the modified Italian IDS9-SF) was equally split into two random halves. Sub-sample 1 from Sample B (Sample B-SS1; $n=257$ ) was used for the EFA, and sub-sample 2 from Sample B (Sample B-SS2; $n=257$ ) was used for the CFA. Descriptive analyses were also repeated to investigate asymmetry and kurtosis. In the modified version, skewness and kurtosis was inferior to the absolute values of 3.0 and 8.0, respectively (and in the modified version, the items were distributed in a non-normal way); all the items had good factor loading (i.e., $\lambda \mathrm{ij} \geq .50$; Ferguson and Cox 1993) and a satisfactory correlation with the total score of the IDS9-SF (i.e., >0.50). The modified Italian IDS9-SF reported the following indicators for EFA on Sample B-SS1: KMO test $=0.90$, RMSEA $=0.06, \mathrm{CFI}=$ 0.99 , and GFI $=1$. The analysis was also conducted using PA with DWLS estimator with polychoric correlations ( $\mathrm{Li} 2015$ ).

Results provided a one-factor solution for Sample B-SS1 and confirmed the unidimensional properties of the modified IDS9-SF. These results supported the factor validity of the IDS9-SF test because the estimated common variance (ECV) explained $68.2 \%$ of the variance for Sample A-SS1 and $68.1 \%$ for Sample B-SS1, with acceptable standardized item loadings in both sub-samples (range $\min =0.608$, to $\max =0.877$, i.e., $\lambda \mathrm{ij} \geq .50$; Ferguson and Cox 1993). Furthermore, both sub-Sample A-SS1 and Sample B-SS1 had eigenvalues $>1$ in a single factor model (see Gorsuch 1983) which indicates one factor as the optimal model to use. More specifically, the eigenvalue for Sample A-SS1 $=5.20$ (proportion of variance $=.578$ ), and the eigenvalue for Sample B-SS1 $=5.19$ (proportion of variance $=.577$ ).

The results demonstrated that the modified Italian IDS9-SF provided slightly better results than the original translation of the Italian IDS9-SF, although both scales are valid (i.e., RMSEA $<0.08$ acceptable fit, GFI $>0.9$ satisfactory fit (Greenspoon and Saklofske 1998)), from the point of view of statistical model fit. Table 2 provides a summary of the EFA results obtained from the nine items of the Italian IDS9-SF for Sample A (original Italian IDS9-SF) and Sample B (modified Italian IDS9-SF). The results refer to the users' internet use during the past 12 months, and $\lambda$ refers to the factor loadings. All factor loadings were statistically significant at $p<0.001$. 


\section{Confirmatory Factor Analyses}

CFA was conducted using the unidimensional model on both Sample A-SS2 (original Italian IDS9-SF; $n=480$ ) and Sample B-SS2 (modified Italian IDS9-SF; $n=257$ ). The structural model was tested using the goodness of fit (GOF) indices using the DWLS estimator. Since there is no univocal academic consensus about the indicators to evaluate a model reliability (Bollen and Long 1993; Boomsma 2000; Hoyle and Panter 1995), goodness of fit was evaluated using several indicators as in the EFAs. Chi-square is very sensitive to the size of the sample, so several indices were used (Kline 2016). The results for Sample A-SS2 were $\mathrm{RMSEA}=0.064, \mathrm{SRMR}=0.060, \mathrm{CFI}=0.99$, and TLI $=0.99\left(\chi^{2}=80.05, \mathrm{df}=27, p<.01\right)$ and for Sample B-SS2 were RMSEA $=0.06, \mathrm{SRMR}=0.05, \mathrm{CFI}=0.99$, and TLI $=0.98\left(\chi^{2}=\right.$ $64.34, \mathrm{df}=27, p<0.01)$. Since the results obtained from EFA and CFA reported comparable results for the (i) model fit indicators, (ii) and factor loadings (but with stronger reliability in terms of skewness and kurtosis for Sample B), the reliability analysis, convergence validity, and criterion validity were carried out on Sample B only (i.e., with the modified Italian IDS9$\mathrm{SF})$.

\section{Reliability Analysis}

The reliability of the modified Italian IDS9-SF was assessed using several indices. The Cronbach coefficient was very good $(\alpha=0.862)$ and it could not be improved by the removal of any item. The factor score determinacy was excellent (0.956), well above the suggested threshold of 0.80 (Muthén and Muthén 2012). All the individual items were statistically relevant and positively correlated with the total IDS9-SF score (Item $1, r=0.70$; Item 2, $r=0.70$; Item 3, $r=0.73$; Item 4, $r=0.74$; Item 5, $r=0.66$; Item 6, $r=0.70$; Item 7, $r=0.57$; Item $8, r=0.69$; Item 9, $r=0.75$ ). Overall, these results strongly support the adequacy and reliability of the unidimensional factor solution of the modified Italian IDS9-SF in the present sample. The composite reliability coefficient was also very good (0.85) and well above the 0.70 threshold (Fornell and Larcker 1981).

Table 2 Exploratory factor analysis model fit indices summary of the Italian nine-item Internet Disorder Scale (sub-Samples 1 and 2)

\begin{tabular}{lll}
\hline Model fit indicators & Result (Sample A, sub-sample 1) $n=480$ & Result (Sample B, sub-sample 1) $n=257$ \\
\hline KMO & 0.90 & 0.90 \\
ECV & $68.2 \%$ & $68.1 \%$ \\
RMSEA & 0.06 & 0.06 \\
RMSR & 0.07 & 0.05 \\
AGFI & 1 & 1 \\
GFI & 1 & 1 \\
NNFI & 0.97 & 0.97 \\
CFI & 0.98 & 0.99 \\
WRMR & 0.05 & 0.05 \\
\hline
\end{tabular}

$K M O$ : Kaiser-Meyer-Olkin, $E C V$ : explained common variance \%, RMSEA: root mean square error of approximation, RMSR: root mean square of residuals, $A G F I$ : adjusted goodness of fit index, GFI: goodness of fit index, WRMR: weighted root mean square residual, NNFI: non-normed fit index 


\section{Construct, Convergence, and Criterion Validity}

The total IDS9-SF score on the modified Italian version was positively correlated (to investugate construct, convergent, and criterion validity [Cronbach and Meehl 1955; Field 2013]) with the frequency of online socialization $(r=0.150)$, frequency of access to online pornography $(r=0.118)$, and degree of anxiety associated with performing actions such as speaking in public $(r=0.252)$. The total score of the modified Italian IDS9-SF was also positively (albeit weakly) correlated with online gaming frequency $(r=0.115)$ and frequency of using electronic devices $(r=0.254)$. The total modified Italian IDS9-SF score also positively correlated with the perceived importance of the internet to the user $(r=0.300)$. The total score on the modified Italian IDS9-SF also positively correlated with the online socialization frequency $(r=0.200)$. Total score of the modified Italian IDS9-SF was negatively correlated with the degree of perceived life satisfaction $(r=-0.356)$, online shopping frequency $(r=-0.003)$, and age of the user $(r=-0.022)$. IDS9-SF total score was also negatively correlated with smoking frequency $(r=-0.016)$, alcohol consumption $(r=-0.42)$, and illicit drugs/narcotics use $(r=-$ 0.017). IDS9-SF total score was also negatively correlated with the age of participants $(r=-0.022)$. Regarding demographic aspects, there were no significant gender differences on total IDS9-SF score $(t=1.586, \mathrm{df}=548 ; p=.1133)$ and no significant correlation between educational level and total IDS9-SF score $(r=-0.098)$. However, results showed that the modified Italian IDS9-SF score was positively correlated with scores on both the Italian BSMAS $(r=0.727)$ and the Italian IGDT9-SF $(r=0.400)$.

\section{Discussion}

The primary aims of the present study were to validate the Italian IDS9-SF through exploratory and confirmatory factor analysis and to explore its convergent, construct, and criterion validity. This was investigated in the Italian context utilizing two samples comprising 1477 participants and psychometrically testing two alternative versions of Italian IDS-SF (i.e., the "original" translated version and the modified translated versions where two items were slightly modified (i.e., Items 7 and 9)). In the original version, these two items were problematic in terms of asymmetry and kurtosis ( $>3$ and $>11$, respectively). This led to a slight modification of the items, and the modified version of the IDS9-SF was psychometrically tested on a new sample of Italian adults.

These slight modifications were made because the authors thought that, in the Italian context, the word "deceived" ("ingannare") might have been associated with fraud and deception, which would change the perceived meaning of Item 7. Similarly, the wording "jeopardized or lost" ("compromettere o perdere") could have been interpreted as a strongly perceived threat or a loss that already occurred, which may have not been easily admitted or accepted by someone with an internet disorder. In the modified version, the two slightly reformulated elements showed a more uniform distribution (i.e., all items with lower asymmetry and kurtosis in absolute values of 3 and 8). This led to the conclusion that the modified form of the Italian IDS9-SF was more reliable than the original Italian version and that the translation took into account the Italian internet users' context and language sensitivity and provided more robust psychometric results. 
Robust testing was investigated utilizing EFA, CFA, reliability analysis, nomological analysis, convergence validity, and criterion validity. The results of the exploratory and confirmatory factor analyses and the nomological validation provided very good evidence concerning the construct validity of the instrument. In terms of factorial structure, the results obtained in the present study mirror those reported in previous studies (Pontes and Griffiths 2015, 2016), which also reported a unidimensional factorial structure for the nine internet use disorder criteria. The psychometric testing also supported the internal consistency of the Italian IDS9-SF because the Cronbach's alpha and determination factor were both sufficiently high.

Positive correlations were found between the modified Italian IDS9-SF, and Italian versions of both the BSMAS (assessing social media addiction), and the IGDS9-SF (assessing internet gaming disorder), although there was a weaker correlation between internet disorder (ID) and internet gaming disorder (IGD). The results demonstrate that the two constructs (ID and IGD) are conceptually and behaviorally distinct, a finding which has been demonstrated empirically in other studies (Montag et al. 2015; Griffiths and Pontes 2014; Király et al. 2014). The higher correlation between the IDS9-SF and the BSMAS demonstrates that problematic internet use is more strongly correlated with problematic use of social media which is what would be expected given that social media use is an online-only activity compared with gaming (which is not). However, it should also be noted that the high correlation may have been because the sample had disproportionately more females, and research has shown that females are more likely to be at risk for social media addiction whereas males are more likely to be at risk for gaming addiction (Andreassen et al. 2016).

Other results in the present study match those found in previous research. Weinstein et al. (2015) and Rusconi et al. (2012) both found a positive correlation between the level of social anxiety and internet addiction, while Wartberg et al. (2015) underlined how greater internet use is associated with lower life satisfaction. The present study found a positive correlation between ID and both higher online socialization frequency and social anxiety, and a negative correlation between ID and life satisfaction. Consequently, the perceived importance the internet has on individuals increases with their internet use, while their general life satisfaction decreases with increased internet use. Such findings have also been reported in previous studies (e.g., Cho et al. 2014; Rücker et al. 2015). ID was negatively correlated with the age of the participant. This suggests that with increasing age, the negative use of the internet and/or its related applications decreases. This is in agreement with previous literature, which reports older generations tend to use the internet primarily as a source of information (e.g., Andone et al. 2016).

In the present study, ID was negatively correlated with online shopping frequency and negatively correlated (albeit weakly) with the use of potentially addictive substances (i.e., cigarettes, alcohol, and drugs). Previous literature has found a positive correlation between ID and online shopping (Trotzke et al. 2015) and between ID and cigarettes, alcohol, and drug consumption (i.e. Cho et al. 2014; Rücker et al. 2015). These differences in findings could be due to cultural differences among the investigated countries (i.e., USA, India, UK, and China).

\section{Limitations and Conclusion}

Despite the fact that the present study confirmed the IDS9-SF's very good psychometric properties, the study has its limitations. The participants comprised a self-selected sample and were therefore not representative of the Italian population. The data were based on 
self-report cross-sectional data from a modestly sized sample of participants (with a bias toward female participants) and included some single-item measures (e.g., quality of life and sociability). Therefore, the data are subject to well-known social desirability and recall biases, as well as being unable to determine any causality between the variables (e.g., age and internet disorder). Further research needs to be carried out on more representative Italian samples including samples with a more even spread of males and females. This is needed to confirm the Italian IDS9-SF's validity and robustness. Longitudinal studies are needed to address relationships between ID and other variables (e.g., factors concerning family and societal background, educational level, work satisfaction, age). Despite these limitations, the modified Italian IDS9-SF appears to be a psychometrically robust measure for assessing the risk of internet disorder among Italian adults.

\section{Compliance with Ethical Standards}

Conflict of Interest The authors declare that they do not have any interests that could constitute a real, potential, or apparent conflict of interest with respect to their involvement in the publication. The authors also declare that they do not have any financial or other relations (e.g., directorship, consultancy, or speaker fee) with companies, trade associations, unions, or groups (including civic associations and public interest groups) that may gain or lose financially from the results or conclusions in the study. Sources of funding are acknowledged.

Ethical Approval All the procedures carried out in the present study were in accordance with the Helsinki declaration and with the approval of the research team's institutional research committee. All participants were assured that their data were anonymous and confidential and that they could withdraw their participation at any time.

Informed Consent Informed consent was obtained from all participants.

\section{APPENDIX}

\section{IDS9-SF Original Italian version}

1. Il tuo comportamento online ti preoccupa? (Alcuni esempi: tendi a ripensare alle precedenti sessioni online oppure ad anticipare la successiva? Ritieni che l'attività online sia diventata dominante nella tua quotidianità?).

2. Ti senti più irritabile, ansioso e/o triste quando provi a smettere di navigare in internet o a ridurne l'uso?

3. Hai necessità di trascorrere sempre più tempo online per riuscire a sentirti soddisfatto $o$ felice?

4. Hai difficoltà a controllare, diminuire e/o cessare l'uso di internet?

5. L'attività online ti ha fatto perdere interesse per gli hobby che avevi prima e per altri modi di impiegare il tempo libero?

6. Hai continuato a connetterti online, pur sapendo che ciò stava danneggiando i tuoi rapporti interpersonali?

7. Hai ingannato qualcuno dei tuoi familiari, terapisti o altre persone a causa della quantità di tempo che trascorri online?

8. Vai online per evadere dalla realtà o sentirti meglio (es. senso di impotenza, senso di colpa, ansia)? 
9. Hai compromesso o perso una relazione importante, la carriera o un'opportunità di formazione a causa dell'uso di internet?

\section{APPENDIX}

\section{IDS9-SF Modified Italian version}

1. Il tuo comportamento online ti preoccupa? (Alcuni esempi: tendi a ripensare alle precedenti sessioni online oppure ad anticipare la successiva? Ritieni che l'attività online sia diventata dominante nella tua quotidianità?).

2. Ti senti più irritabile, ansioso e/o triste quando provi a smettere di navigare in internet o $\mathrm{a}$ ridurre l'uso?

3. Hai necessità di trascorrere sempre più tempo online per riuscire a sentirti soddisfatto o felice?

4. Hai difficoltà a controllare, diminuire e/o cessare l'uso di internet?

5. L'attività online ti ha fatto perdere interesse per gli hobby che avevi prima e per altri modi di impiegare il tempo libero?

6. Hai continuato a connetterti online, pur sapendo che ciò stava danneggiando i tuoi rapporti interpersonali?

7. Hai mentito ai tuoi familiari, amici, terapisti o altre persone sulla quantità di tempo trascorso online su internet?

8. Vai online per evadere dalla realtà o sentirti meglio (es. senso di impotenza, senso di colpa, ansia)?

9. Hai messo a rischio o hai compromesso una relazione importante, la tua carriera o i tuoi studi a causa del tuo uso di internet (ad esempio un uso eccessivo)?

Open Access This article is licensed under a Creative Commons Attribution 4.0 International License, which permits use, sharing, adaptation, distribution and reproduction in any medium or format, as long as you give appropriate credit to the original author(s) and the source, provide a link to the Creative Commons licence, and indicate if changes were made. The images or other third party material in this article are included in the article's Creative Commons licence, unless indicated otherwise in a credit line to the material. If material is not included in the article's Creative Commons licence and your intended use is not permitted by statutory regulation or exceeds the permitted use, you will need to obtain permission directly from the copyright holder. To view a copy of this licence, visit http://creativecommons.org/licenses/by/4.0/.

\section{References}

Alimoradi, Z., Lin, C.-Y., Broström, A., Bülow, P. H., Bajalan, Z., Griffiths, M. D., Ohayon, M. M., \& Pakpour, A. H. (2019). internet addiction and sleep problems: A systematic review and meta-analysis. Sleep Medicine Review, 47, 51-61. https://doi.org/10.1016/j.smrv.2019.06.004.

Alpaslan, A. H., Avci, K., Soylu, N., \& Guzel, H. I. (2015). The association between problematic internet use, suicide probability, alexithymia and loneliness among Turkish medical students. Journal of Psychiatry, 18(208). https://doi.org/10.4172/psychiatry.1000208.

American Psychiatric Association. (2013). Diagnostic and statistical manual of mental disorders (5th ed.). Arlington, VA: American Psychiatric Publishing. 
Andone, I., Błaszkiewicz, K., Eibes, M., Trendafilov, B., Montag, C., \& Markowetz, A. (2016). How age and gender affect smartphone usage. In: Proceedings of the 2016 ACM international joint conference on pervasive and ubiquitous computing: adjunct (pp. 9-12). Heidelberg, Germany. ACM. doi: https://doi. org/10.1145/2968219.2971451.

Andreassen, C. S., Billieux, J., Griffiths, M. D., Kuss, D. J., Demetrovics, Z., Mazzoni, E., \& Pallesen, S. (2016). The relationship between addictive use of social media and video games and symptoms of psychiatric disorders: A large-scale cross-sectional study. Psychology of Addictive Behaviors, 30, 252-262. https://doi. org/10.1037/adb0000160.

Banjanin, N., Banjanin, N., Dimitrijevic, I., \& Pantic, I. (2015). Relationship between internet use and depression: Focus on physiological mood oscillations, social networking and online addictive behavior. Computers in Human Behavior, 43, 308-312. https://doi.org/10.1016/j.chb.2014.11.013.

Beaton, D. E., Bombardier, C., Guillemin, F., \& Ferraz, M. B. (2000). Guidelines for the process of cross-cultural adaptation of self-report measures. Spine, 25(24), 3186-3191. https://doi.org/10.1097/00007632200012150-00014.

Block, J. J. (2008). Issues for DSM-V: internet addiction. American Journal of Psychiatry, 165(3), 306-307. https://doi.org/10.1176/appi.ajp.2007.07101556.

Bollen, K. A., \& Long, J. S. (1993). Introduction. In K. A. Bollen \& J. S. Long (Eds.), Testing structural equation models (pp. 1-9). Newbury Park: Sage.

Boomsma, A. (2000). Reporting analyses of covariance structures. Structural Equation Modeling, 7(3), 461-483. https://doi.org/10.1207/S15328007SEM0703 6.

Cerny, C. A., \& Kaiser, H. F. (1977). A study of a measure of sampling adequacy for factor-analytic correlation matrices. Multivariate Behavioral Research, 12(1), 43-47. https://doi.org/10.1207/s15327906mbr1201_3.

Cho, H., Kwon, M., Choi, J. H., Lee, S. K., Choi, J. S., Choi, S. W., \& Kim, D. J. (2014). Development of the internet addiction scale based on the internet gaming disorder criteria suggested in DSM-5. Addictive Behaviors, 39(9), 1361-1366. https://doi.org/10.1016/j.addbeh.2014.01.020.

Cronbach, L. J., \& Meehl, P. E. (1955). Construct validity in psychological tests. Psychological Bulletin, 52(4), 281-302. https://doi.org/10.1037/h0040957.

Davis, R. A. (2001). A cognitive-behavioral model of pathological internet use. Computers in Human Behavior, 17(2), 187-195. https://doi.org/10.1016/S0747-5632(00)00041-8.

Ezoe, S., Toda, M., Yoshimura, K., Naritomi, A., Den, R., \& Morimoto, K. (2009). Relationships of personality and lifestyle with mobile phone dependence among female nursing students. Social Behavior and Personality, 37(2), 231-238. https://doi.org/10.2224/sbp.2009.37.2.231.

Ferguson, E., \& Cox, T. (1993). Exploratory factor analysis: A users' guide. International Journal of Selection and Assessment, 1(2), 84-94. https://doi.org/10.1111/j.1468-2389.1993.tb00092.x.

Field, A. (2013). Discovering statistics using IBM SPSS statistics (4th ed.). London: Sage.

Fornell, C., \& Larcker, D. F. (1981). Evaluating structural equation models with unobservable variables and measurement error. Journal of Marketing Research, 18(1), 39-50. https://doi.org/10.2307/3151312.

Gorsuch, R. L. (1983). Factor analysis (2nd ed.). Hillsdale: Lawrence Erlbaum Associates.

Greenfield, D. N. (1999). Psychological characteristics of compulsive internet use: A preliminary analysis. Cyberpsychology \& Behavior, 2(5), 403-412. https://doi.org/10.1089/cpb.1999.2.403.

Greenspoon, P. J., \& Saklofske, D. H. (1998). Confirmatory factor analysis of the multidimensional Students' life satisfaction scale. Personality and Individual Differences, 25(5), 965-971. https://doi.org/10.1016/S01918869(98)00115-9.

Griffiths, M. D. (1995). Technological addictions. Clinical Psychology Forum, 76, 14-19.

Griffiths, M. D. (1996). internet "addiction": An issue for clinical psychology? Clinical Psychology Forum, 97, 32-36 6.

Griffiths, M. D. (1998). internet addiction: Does it really exist? In J. Gackenbach (Ed.), Psychology and the internet: Intrapersonal, interpersonal and transpersonal applications (pp. 61-75). New York: Academic Press.

Griffiths, M. D. (1999). internet addiction: Fact or fiction? The Psychologist: Bulletin of the British Psychological Society, 12, 246-250.

Griffiths, M. D. (2005). A 'components' model of addiction within a biopsychosocial framework. Journal of Substance Use, 10, 191-197. https://doi.org/10.1080/14659890500114359.

Griffiths, M. D., \& Pontes, H. M. (2014). internet addiction disorder and internet gaming disorder are not the same. Addiction Research and Theory, 5, e124. https://doi.org/10.4172/2155-6105.1000e124.

Griffiths, M. D., Pontes, H. M., \& Kuss, D. J. (2016). Online addictions: Conceptualizations, debates and controversies. Addicta: The Turkish Journal on Addictions, 3(2), 151-164. https://doi.org/10.15805 /addicta.2016.3.0101.

Hair, J., \& Black, W., \& Babin, B., \& Anderson, R. (2009). Multivariate data analysis. London: Prentice Hall.. 
Hoyle, R. H., \& Panter, A. T. (1995). Writing about structural equation models. In R. H. Hoyle (Ed.), Structural equation modeling: Concepts, issues, and applications (pp.158-176). Thousand Oaks, CA: Sage.

IBM Corp. (2011). IBM SPSS statistics for windows, Version 20.0. Armonk, NY: IBM Corp.

Jun, S., \& Choi, E. (2015). Academic stress and internet addiction from general strain theory framework. Computers in Human Behavior, 49, 282-287. https://doi.org/10.1016/j.chb.2015.03.001.

Kaess, M., Parzer, P., Brunner, R., Koenig, J., Durkee, T., Carli, V., \& Wasserman, D. (2016). Pathological internet use is on the rise among European adolescents. Journal of Adolescent Health, 59, 236-239. https://doi.org/10.1016/j.jadohealth.2016.04.009.

Kaiser, H. (1974). An index of factor simplicity. Psychometrika, 39, 31-36. https://doi.org/10.1007 /BF02291575.

Kim, H. Y. (2013). Statistical notes for clinical researchers: Assessing normal distribution using skewness and kurtosis. Restorative Dentistry \& Endodontics, 38(1), 52-54. https://doi.org/10.5395/rde.2013.38.1.52.

Király, O., Griffiths, M. D., Urbán, R., Farkas, J., Kökönyei, G., Elekes, Z., Tamás, D., \& Demetrovics, Z. (2014). Problematic internet use and problematic online gaming are not the same: Findings from a large nationally representative adolescent sample. Cyberpsychology, Behavior and Social Networking, 17(12), 749-754. https://doi.org/10.1089/cyber.2014.0475.

Kline, R. B. (2011). Methodology in the social sciences. Principles and practice of structural equation modeling (3rd ed.). New York: Guilford Press.

Kline, R. B. (2016). Methodology in the social sciences. Principles and practice of structural equation modeling (4th ed.). Guilford press.

Ko, C. H., Hsiao, S., Liu, G., Yen, J., Yang, M., \& Yen, C. (2010). The characteristics of decision making, potential to take risks, and personality of college students with internet addiction. Psychiatry Research, 175, 121-125. https://doi.org/10.1016/j.psychres.2008.10.004.

Lam, L. T., Peng, Z. W., Mai, J. C., \& Jing, J. (2009). Factors associated with internet addiction among adolescents. Cyberpsychology \& Behavior, 12(5), 551-555. https://doi.org/10.1089/cpb.2009.0036.

Lee, J. Y., Park, E. J., Kwon, M., Choi, J. H., Jeong, J. E., Choi, J. S., Choi, S. W., Lee, C. U., \& Kim, D. J. (2014). The difference in comorbidities and behavioral aspects between internet abuse and internet dependence in Korean male adolescents. Psychiatry Investigation, 11(4), 387-393. https://doi.org/10.4306 /pi.2014.11.4.387.

Li, C.-H. (2015). Confirmatory factor analysis with ordinal data: Comparing robust maximum likelihood and diagonally weighted least squares. Behavior Research Methods, 48, 936-949. https://doi.org/10.3758 /s13428-015-0619-7.

Lin, T. T., Chiang, Y. H., \& Jiang, Q. (2015). Sociable people beware? Investigating smartphone versus nonsmartphone dependency symptoms among young Singaporeans. Social Behavior and Personality, 43(7), 1209-1216. https://doi.org/10.2224/sbp.2015.43.7.1209.

Lorenzo-Seva, U., \& Ferrando, P. J. (2006). FACTOR: A computer program to fit the exploratory factor analysis model. Behavior Research Methods, 38, 88-91. https://doi.org/10.3758/BF03192753.

Marks, I. (1990). Behavioural (non-chemical) addictions. British Journal of Addiction, 85(11), 1389-1394. https://doi.org/10.1111/j.1360-0443.1990.tb01618.x.

Monacis, L., Palo, V. D., Griffiths, M. D., \& Sinatra, M. (2016). Validation of the internet gaming disorder scaleshort-form (IGDS9-SF) in an Italian-speaking sample. Journal of Behavioral Addictions, 5(4), 683-690. https://doi.org/10.1556/2006.5.2016.083.

Monacis, L., De Palo, V., Griffiths, M. D., \& Sinatra, M. (2017). Social networking addiction, attachment style, and validation of the Italian version of the Bergen social media addiction scale. Journal of Behavioral Addictions, 6(2), 178-186. https://doi.org/10.1556/2006.6.2017.023.

Montag, C., Bey, K., Sha, P., Li, M., Chen, Y. F., Liu, W. Y., Zhu, Y. K., Li, C. B., Markett, S., Keiper, J., \& Reuter, M. (2015). Is it meaningful to distinguish between generalized and specific internet addiction? Evidence from a cross-cultural study from Germany, Sweden, Taiwan and China. Asia-Pacific Psychiatry, 7(1), 20-26. https://doi.org/10.1111/appy.12122.

Muthèn, B., \& Kaplan, D. (1985). A comparison of some methodologies for the factor analysis of non-normal Likert variables. British Journal of Mathematical and Statistical Psychology, 38(2), 171-189. https://oi. org/10.1111/j.2044-8317.1985.tb00832.x.

Muthén, L. K., \& Muthén, B. O. (2012). Mplus user's guide (seventh ed.). Los Angeles: Muthén \& Muthén.

Petry, N. M., Zajac, K., \& Ginley, M. K. (2018). Behavioral addictions as mental disorders: To be or not to be? Annual Review of Clinical Psychology, 14, 399-423. https://doi.org/10.1146/annurev-clinpsy-032816045120.

Pies, R. (2009). Should DSM-V designate "internet addiction" a mental disorder? Psychiatry (Edgmont), 6(2), 31-37. 
Pontes, H. M., \& Griffiths, M. D. (2015). Measuring DSM-5 internet gaming disorder: Development and validation of a short psychometric scale. Computers in Human Behavior, 45, 137-143. https://doi. org/10.1016/j.chb.2014.12.006.

Pontes, H. M., \& Griffiths, M. D. (2016). The Development and psychometric properties of the internet Disorder Scale-Short Form (IDS9-SF). Addicta: The Turkish Journal on Addictions, 3, 1-16. https://doi.org/10.15805 /addicta.2016.3.0102.

Pontes, H. M., \& Griffiths, M. D. (2017). The development and psychometric evaluation of the internet disorder scale (IDS-15). Addictive Behaviors, 64, 261-268. https://doi.org/10.1016/j.addbeh.2015.09.0030306-4603.

Pontes, H. M., Király, O., Demetrovics, Z., \& Griffiths, M. D. (2014). The conceptualisation and measurement of DSM-5 internet gaming disorder: The development of the IGD-20 test. PLoS One, 9(10), e110137. https://doi.org/10.1371/journal.pone.0110137.

Pontes, H. M., Kuss, D. J., \& Griffiths, M. D. (2015). Clinical psychology of internet addiction: A review of its conceptualization, prevalence, neuronal processes, and implications for treatment. Neuroscience and Neuroeconomics, 4, 11-23. https://doi.org/10.2147/NAN.S60982.

Reed, P., Osborne, L. A., Romano, M., \& Truzoli, R. (2015). Higher impulsivity after exposure to the internet for individuals with high but not low levels of self-reported problematic internet behaviours. Computers in Human Behavior, 49, 512-516. https://doi.org/10.1016/j.chb.2015.03.064.

Rosseel, Y. (2012). Lavaan: An R package for structural equation modeling. Journal of Statistical Software, 48(2), 1-36.

Rücker, J., Akre, C., Berchtold, A., \& Suris, J. C. (2015). Problematic internet use is associated with substance use in young adolescents. Acta Paediatrica, 104(5), 504-507. http://dx.doi. Org/https://doi.org/10.1111 /apa.12971.

Rusconi, A. C., Valeriani, G., Carlone, C., Raimondo, P., Quartini, A., de’ Fornari, M. A. C., \& Biondi, M. (2012). internet addiction disorder e social network: Analisi statistica di correlazione e studio dell'associazione con l'ansia da interazione sociale. Rivista di Psichiatria, 47, 498-508. https://doi. org/10.1708/1178.13056.

Sariyska, R., Reuter, M., Lachmann, B., \& Montag, C. (2015). Attention deficit/hyperactivity disorder is a better predictor for problematic internet use than depression: Evidence from Germany. Journal of Addiction Research and Therapy, 6, 209. https://doi.org/10.4172/2155-6105.1000209.

Shapira, N. A., Goldsmith, T. D., Keck Jr., P. E., Khosla, U. M., \& McElroy, S. L. (2000). Psychiatric features of individuals with problematic internet use. Journal of Affective Disorders, 57(1-3), 267-272. https://doi. org/10.1016/S0165-0327(99)00107-X.

Trotzke, P., Starcke, K., Müller, A., \& Brand, M. (2015). Pathological buying online as a specific form of internet addiction: A model-based experimental investigation. PLoS One, 10(10), e0140296. https://doi.org/10.1371 /journal.pone.0140296.

Wartberg, L., Kriston, L., Kammerl, R., Petersen, K. U., \& Thomasius, R. (2015). Prevalence of pathological internet use in a representative German sample of adolescents: Results of a latent profile analysis. Psychopathology, 48(1), 25-30. https://doi.org/10.1159/000365095.

Weinstein, A., Feder, L. C., Rosenberg, K. P., \& Dannon, P. (2014). internet addiction disorder: Overview and controversies. In K. P. Rosenberg \& L. C. Feder (Eds.), Behavioral addictions (pp. 99-117). San Diego, CA: Academic Press.

Weinstein, A., Dorani, D., Elhadif, R., Bukovza, Y., \& Yarmulnik, A. (2015). internet addiction is associated with social anxiety in young adults. Annals of Clinical Psychiatry, 27(1), 2-7. https://doi.org/10.1093 /med/9780199380183.003.0001.

Young, K. S. (1998). internet addiction: The emergence of a new clinical disorder. CyberPsycholgy \& Behavior, 1, 237-244. https://doi.org/10.1089/cpb.1998.1.237.

Publisher's Note Springer Nature remains neutral with regard to jurisdictional claims in published maps and institutional affiliations. 


\section{Affiliations}

\section{Paolo Soraci ${ }^{1}$ - Ambra Ferrari ${ }^{2}$ - Enrico Bonanno ${ }^{3}$ - De Pace Rosanna ${ }^{1}$ - Emanuela Repice $^{1} \cdot$ Mark D. Griffiths ${ }^{4}$}

Paolo Soraci

paolo.soraci85@gmail.com

Ambra Ferrari

a.ferrari50@ campus.unimib.it

Enrico Bonanno

enrico.bonanno@list.lu

De Pace Rosanna

Rosannadepace@ libero.it

Emanuela Repice

emanuelarepice@gmail.com

1 ASP-CSM SUD, Reggio Calabria, Italy

2 Department of Human Science for Education 'Riccardo Massa', Università degli Studi di Milano Bicocca, Milan, Italy

3 Department of Environmental Research and Innovation, Luxembourg Institute of Science and Technology, Belvaux, Luxembourg

4 Behavioural Addiction International Gaming Research Unit, Psychology Department, Nottingham Trent University, Burton Street, Nottingham NG1 4FQ, UK 